\title{
International Journal of Scientific Research and Innovative Studies
} www.bluepenjournals.org/ijsris

\section{Factors affecting minimum wage in developed and less developed countries}

\section{Nikolaos Giovanis ${ }^{1}$, Christos Konstantinidis $^{1 \star}$ and Maria Tsiouni ${ }^{2}$}

\author{
${ }^{1}$ School of Business Administration, International Hellenic University, Serres, Greece. \\ ${ }^{2}$ Agricultural Economics, School of Agriculture, International Hellenic University, Thessaloniki, Greece.
}

\begin{tabular}{ll}
\hline Article History & ABSTRACT \\
\hline Received 26 May, 2021 & $\begin{array}{l}\text { Minimum wage has been a crucial topic between the academics, trying to } \\
\text { Received in revised form 28 }\end{array}$ \\
June, 2021 & $\begin{array}{l}\text { determine the factors that has effect on it. The aim of this study is concerned with } \\
\text { the ways some macroeconomic factors in both developed and less developed } \\
\text { countries affect minimum wage. Samples were assembled and divided in two } \\
\text { groups: the developed and the less developed countries. The methods used in }\end{array}$ \\
Keywords: 2021 & $\begin{array}{l}\text { this study were descriptive statistics and multiple regression analysis. The main } \\
\text { Minimum wage, }\end{array}$ \\
Regression analysis, & $\begin{array}{l}\text { results obtained in this study show that factors such as GDP head, income and } \\
\text { density have positive correlations with minimum wage in developed countries. }\end{array}$ \\
Developed countries, & $\begin{array}{l}\text { While in the less developed countries, the analysis was not possible due to the } \\
\text { Less developed }\end{array}$ \\
countries. & $\begin{array}{l}\text { Durbin-Watson test. Further studies will be conducted to resolve this in other to } \\
\text { have a comprehensive comparison between developed and less developed } \\
\text { countries. }\end{array}$ \\
Article Type: &
\end{tabular}

\section{INTRODUCTION}

Over the last few decades the minimum wage is one of the most debated issues among both employees and politicians and has occupied a large part of the literature (Brutel, 2019). Although the majority of studies have focused on employment effects, recent research highlights the importance of different factors such as working hours, productivity, profits and prices (Metcalf, 2008; Schmitt, 2015; Hirsch et al., 2015; Low Pay Commission, 2015).

The introduction of minimum wage in most countries was a result of the social dimension that its imposition suggests. Typical is the statement of the Prime Minister of Luxemburg and President of the European Council in May 2006, Jean Claude Junker, when he called, "the creation of a European minimum wage according to which every worker should be entitled to a decent wage".

However apart from the social aspect of the provision of the minimum wage the discussion concerns, the possible increase of the productivity of the worker, through the adoption of it, or vice versa of the increase of inflation

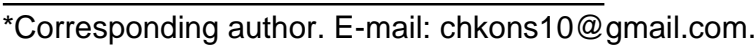

or even unemployment. Traxler et al. (2001), trying to sum up the related with the labor relations and macroeconomic performance literature, distinguished the differences in the approach to enforcement measures - such as the minimum wage - and the impact on macroeconomic parameters such as worker efficiency, unemployment and inflation trade union approach. They concluded that the neoliberal approach believes that the macroeconomic parameters will be deteriorated, the neoclassical ones that it will not play (the adoption of the minimum wage) any essential role in shaping them, while the trade union approach considers its existence beneficial.

Saget (2008) concludes that there are "maxi minimum wages" and "mini minimum wages" between countries in the sense that in some countries the minimum wage is very "close" to the average wage while in some other countries it is far below the average salary. Typical examples of the first group of countries are usually low-income countries such as the Philippines, where the minimum wage is $94 \%$ of the average wage, and Paraguay and Mauritius with $99 \%$ and $79 \%$ respectively. In the second group of countries with "mini minimum wage" are countries with high -basically- per capita income such as the United 
States of America with the percentage of the minimum wage being at $0.29 \%$ of the average wage, Japan with 0.35 and England with 0.55 .

Regardless of the adoption of the positive or negative consequences of the existence of the minimum wage, however, it is generally accepted the debate - among Academics - that it affects to some extent on certain macroeconomic indicators. On the other hand, if it shapes - to some extent - the prices of some indicators, one would assume that each country's price is influenced by those indicators. But it creates the question of how is the minimum wage determined between the various fiscal states that have adopted it. One of the key arguments for the benefits of raising the minimum wage includes the fact that employers invest in increasing employee qualifications through their training and adopt a policy of quality in their market and production of products by raising wage rates (Wilkinson, 1983; Brosnan and Wilkinson, 1988; Burchell et al., 2003; Deakin and Wilkinson, 2005).

According to Edwards and Gilman (1999), Brosnan (2003) and Rubery (1997), the level of the minimum wage is also influenced by historical assumptions, social customs, and values of justice, which are social, economic, and political factors.

Minimum wage laws are used in most developed and less developed countries to achieve a number of policy objectives, and while there are large differences between countries, wage legislation often overlaps. Most of the stated objectives are to ensure that vulnerable workers are protected from extreme low wages, redistributing income from employers to low-wage workers, and boosting productivity. The use of wage floors comes with risks as well, and country-level legislation recognizes these tradeoffs in most cases. These costs can include increased unemployment in certain settings, shortened work hours that disadvantage workers, and the shift from formal to informal employment-where livelihoods are often more precarious (Bhorat et al., 2017).

As regards, Forth and Millward (2000) and Brown et al. (2004) a key factor in determining wages, is the cost of living. Bryson and Forth (2008) conclude that the way remuneration is applied is generally the result of various influences. A wage is not solely determined by labor market forces as predicted by the model, but also by negotiations between employees and employers, as well as by political decisions.

Raurich et al. (2009) provided evidence on the factors influencing wage setting in the Spanish private sector, including variables such as employment level, real gross domestic product and average productivity as potential determinants of the minimum wage, while Bayo-Moriones et al. (2013), claimed that there are two factors that drastically affect the level of the minimum wage: the per capita income per employee and the level of the average wage. Brutel (2019) found that the minimum wage in Germany has increased hours wages significantly while the effect on monthly salaries has been less substantial.

For the reasons referred above we tried to conduct a research that has as its ultimate goal to find the factors that determine the level of the minimum wage and to investigate the relationship between the minimum wage and various macroeconomic variables as well as various contexts in developed and less developed countries which has a great interest both for academics and policy makers. The first sample of the survey concerns countries with high per capita income and the second countries with low per capita income in an attempt to interpret the reasons for differentiating the minimum wage. At the same time, the degree and magnitude of the impact of each variable in terms of predictability and usefulness in the model are examined.

The following sections provide an overview of the research methodology, followed by the analysis and presentation of the results as well as the control of the assumptions. Conclusions as well as implications and limitations of the research follow.

\section{RESEARCH METHODOLOGY}

The research which took place intended to predict the numerical value of the minimum wage, which is valid and therefore probably valid in the future, through data related to the country in question and have a negative or positive effect on the development of this price. It was conducted in two samples. The first sample concerned the developed countries and the second the less developed ones. The index used to make this distinction was derived from the Net National Income per Capita index and (the average of its observed value of all the countries included in the survey) the country was ranked in the first category, while on the contrary if it was less than 100 in the second.

Since then the majority of the studies was based on panel data and time series, in the current research we used the multiple linear regressions to predict the value of the dependent variable. In this way, given the values of the independent variables, we can in each case predict the value of the dependent variable. The independent variables used to determine the values of the dependent variable were derived from macroeconomic data and other factors of the various Member States included in the equation model and obtained from the site of the Organization for Economic Co-operation and Development (2020), retrieved on 18-10-2020 as well as from the site of the International Labour Office, Laborsta (2020) retrieved on 16-9-2020. So, taking account the above referred sources the variables which are included in our model are described in Table 1.

"Minimum wages in US \$ constant prices at 2019" (whose name in the regression analysis is min wage) is the variable whose value we try to capture in each case. Beyond the fact that it serves the purpose of multiple linear 
Giovanis et al. $\quad 3$

Table 1. Independent variables.

\begin{tabular}{ll}
\hline Description & Name in the model \\
\hline Union density & Density \\
Unemployment rate & Unemployed \\
General government fiscal balance as a \% of GDP & Balance \\
Gross Domestic Product per head US \$ & GDP_head \\
Health expenditure .Share of gross domestic product & Health_exp \\
Long Term Interest Rate & Interest \\
Total Central Government debt \% GDP & Debt \\
Strictness of employment protection. Individual and & Strictness \\
collective dismissals (regular contracts) & \\
\hline
\end{tabular}

Table 2. Economically developed countries.

\begin{tabular}{lcc}
\hline State & Years of reporting & Cases \\
\hline Australia & $1999-2019$ & 21 \\
Austria & $1999-2019$ & 21 \\
Belgium & $1999-2019$ & 21 \\
Canada & $1999-2019$ & 21 \\
Denmark & $1999-2019$ & 21 \\
Finland & $1999-2019$ & 21 \\
France & $1999-2019$ & 21 \\
Germany & $1999-2019$ & 21 \\
Iceland & $1999-2019$ & 21 \\
Ireland & $1999-2019$ & 21 \\
Italy & $1999-2019$ & 21 \\
Luxemburg & $1999-2019$ & 21 \\
Netherlands & $1999-2019$ & 21 \\
Norway & $1999-2019$ & 21 \\
Sweden & $1999-2019$ & 21 \\
Switzerland & $1999-2019$ & 21 \\
United Kingdom & $1999-2019$ & 21 \\
USA & $1999-2019$ & 21 \\
Total & & 378 \\
\hline
\end{tabular}

regression (Dafermos, 2005), the following reasons explain the choice: a) It is arithmetic type, b) Its uncontested measure (there is no less- less- middle in this category), c) It obtains the maximum number of cases for entry in regression model (378) -in both samples- because there is a numerical quotation of the minimum wages in almost all cases.

In this way we created a database for statistical processing with 378 cases as shown in Table 2 and with another 378 cases as shown in Table 3 (that is, a total of 756 cases). These cases concern the member states of the Organization for Economic Co-operation and Development (OECD) and are analyzed in each country in the years from 1999 to 2019, in an effort to ensure that the 21-year data set provides a large number of cases to be estimated in the regression analysis.

If the observed level of statistical significance is less than the level I set, then the variable is included in the model. In this process we kept the predetermined $5 \%$ that the program theoretically sets.

\section{RESULTS}

This number (378 cases) meets the investigation's requirements. Field (2000) argues that a reliable 
Table 3. Economically less developed countries.

\begin{tabular}{lcc}
\hline State & Years of reporting & Cases \\
\hline Chile & $1999-2019$ & 21 \\
Czech Republic & $1999-2019$ & 21 \\
Estonia & $1999-2019$ & 21 \\
Greece & $1999-2019$ & 21 \\
Hungary & $1998-2018$ & 21 \\
Israel & $1999-2019$ & 21 \\
Japan & $1999-2019$ & 21 \\
Korea & $1999-2019$ & 21 \\
Latvia & $1999-2019$ & 21 \\
Lithuania & $1999-2019$ & 21 \\
Mexico & $1999-2019$ & 21 \\
New Zealand & $1999-2019$ & 21 \\
Poland & $1999-2019$ & 21 \\
Portugal & $1999-2019$ & 21 \\
Slovakia & $1999-2019$ & 21 \\
Slovenia & $1999-2019$ & 21 \\
Spain & $1999-2019$ & 21 \\
Turkey & $1999-2019$ & 21 \\
Total & & 378 \\
\hline
\end{tabular}

Table 4. Descriptive statistics.

\begin{tabular}{lccc}
\hline & Mean & Std. Deviation & N \\
\hline Minimum wages in US \$ constant prices at 2018 & 20332.11 & 2146.410 & 19 \\
Union density & 26.85816 & 15.139093 & 19 \\
Unemployment rate & 7.305 & 2.7902 & 19 \\
General government fiscal balance as a \% of GDP & -4.8347 & 3.92075 & 19 \\
Gross Domestic Product per head US \$ & 40767.89 & 4351.614 & 19 \\
Health expenditure. Share of gross domestic product & 9.484 & 1.1829 & 19 \\
Long Term Interest Rate & 4.1353 & 0.75611 & 19 \\
Total Central Government debt \% GDP & 58.621 & 20.6223 & 19 \\
Strictness of employment protection. Individual and & 1.9463 & 0.66684 & 19 \\
collective dismissals (regular contracts) & & & 19 \\
\hline
\end{tabular}

regression model requires 10 observations for each independent variable ( 8 independent variables were introduced into the model), which means that it must be at least 80 (in our case it is 378), while Coakes and Stead (1999) consider that this number must be less than 5 (in our case 50).

In Table 4, we find that out of the 378 cases that we introduced in the model, and according to the method used for the regression analysis, that is the stepwise, 19 finally participated, while the mean of the independent variable is 20332,11 (Nurosis, 2002).

In Table 5 where the first and second columns list the values of the correlations of the independent variables with the dependent (min_wage) entitled Pearson Correlation, we observe that the highest level of correlation with the dependent variable is shown by the variable strictness with Pearson $r=84.8 \%$ and absolute value $|0.848|$, followed by the variable interest with Pearson $r=45.5 \%$ while the lowest correlation value is noted in the variable density with $2.9 \%$.

In the third and fourth column (Sig. 1-tailed) the correlation relationship of the independent variables with each other is examined. According to Dafermos (2005) a good linear regression analysis requires independent predictors not to have a high correlation with each other. So if we check the existence of a relation between them 
Table 5. Correlation.

\begin{tabular}{lclc}
\hline Pearson Correlation min_wage & 1.000 & Sig. (1-tailed) min_wage & - \\
\hline Density & 0.029 & Density & 0.453 \\
Unemployed & -0.341 & Unemployed & 0.076 \\
Balance & 0.425 & Balance & 0.055 \\
GDP_head & 0.373 & GDP_head & 0.058 \\
Health_exp & 0.424 & Health_exp & 0.056 \\
Interest & -0.455 & Interest & 0.053 \\
Debt & 0.142 & Debt & 0.282 \\
Strictness & 0.848 & Strictness & 0.051 \\
\hline
\end{tabular}

Table 6. Variables entered/removed ${ }^{\mathrm{a}}$.

\begin{tabular}{cll}
\hline Model & Variables entered & Method \\
\hline 1 & Strictness & Stepwise(Criteria: \\
2 & Density & Probability-of- F-to- \\
3 & GDP_Head & Enter $<=0,50$, \\
4 & Balance & Probability-of-F-to-remove $>=0,100$ \\
\hline
\end{tabular}

aDependent Variable: Min_wage.

Table 7. Summary of indicators of reciprocating model.

\begin{tabular}{ccccccc}
\hline Model & R & R square & Adjusted R square & R Square change & Sig. F change & Durbin Watson \\
\hline 1 & $0.848(\mathrm{a})$ & 0.720 & 0.703 & 0.720 & 0.000 & 1.990 \\
2 & $0.977(\mathrm{~b})$ & 0.955 & 0.950 & 0.235 & 0.000 & \\
3 & $0.983(\mathrm{c})$ & 0.967 & 0.960 & 0.120 & 0.039 & \\
4 & $0.992(\mathrm{~d})$ & 0.985 & 0.980 & 0.180 & 0.001 & \\
\hline
\end{tabular}

our zero and alternative hypothesis are formulated as follows:

Ho: There is no linear relationship between the independent variables

H1: There is a linear relationship between the independent variables

Because the observed levels of statistical significance are in all cases sign. (1-tailed) $>5 \%$ with a higher value in the variable density $(0.453$ or $45.3 \%)$ and a lower value in the variable strictness $(0.051$ or $5.1 \%)$, the zero relation cannot be rejected.

Table 6 shows which predictors were entered and removed from the model using the Stepwise Method, in which time and with which criteria. Therefore, we observe that 4 predictors from 8 were chosen with the variable strictness being introduced first in the model, which also had the highest absolute correlation value with the dependent variable $|0.848|$ (Table 5), while the last one manages to enter the balance variable.

(a). Predictors: (Constant), strictness

(b). Predictors: (Constant), strictness, density

(c). Predictors: (Constant), strictness, density, GDP_head

(d). Predictors: (Constant), strictness, density, GDP_head, balance

(e). Dependent Variable: min_wage

Table 7 provides a summary of indicators of our reciprocating model, according to the Stepwise method. We observe that the method evolved into four phases, as many as the independent variables we had to allocate and in each phase created a new model. In this table it is shown that the first model created with only the introduction of the variable strictness can explain $72.0 \%$ of the dispersion (determination coefficient $\mathrm{R}^{2}=0.720$ ) while the addition of the variable density in model 2 , results in increase of the explained dispersion to $95.5 \%$.

Respectively in the 3rd model the variable GDP_head 
Table 8. Coefficients ${ }^{a}$

\begin{tabular}{|c|c|c|c|c|c|c|}
\hline \multirow{2}{*}{ Model } & & \multicolumn{2}{|c|}{ Unstandardized coefficients } & \multirow{2}{*}{$\mathbf{T}$} & \multicolumn{2}{|c|}{ Collinearity statistics } \\
\hline & & B & Std. Error & & Tolerance & VIF \\
\hline \multirow[t]{5}{*}{4} & (Constant) & 7535.30 & 819.008 & 9.201 & & \\
\hline & Strictness & 3723.29 & 143.244 & 25.993 & 0.555 & 1.802 \\
\hline & Density & 79.274 & 5.858 & 13.532 & 0.644 & 1.554 \\
\hline & GDP_head & 0.073 & 0.018 & 4.119 & 0.841 & 1.189 \\
\hline & Balance & -88.046 & 22.013 & -4.000 & 0.680 & 1.471 \\
\hline
\end{tabular}

aDependent Variable: min_wage.

increases the dispersion to $96.7 \%$, while finally in the 4 th model with four predictors (strictness, density, GDP_head, balance) it is able to explain $98.5 \%$ of the total dispersion in the dependent variable min_wage. So if we analyze the results of model 4 which is also the model with the largest number of predictors (4), we conclude to the following; the coefficient of multiple correlation $\mathrm{R}$ which shows the correlation between the observed and the predicted values of the dependent variable is very high and takes the value $R=99.2 \%$. The coefficient of multiple determinations $R^{2}$ which in the case of the 4th regression model is equal to $98.5 \%$, shows the percentage of high dispersion credited to the dependent variable min_wage from the total of 4 independent variables strictness, density, GDP_head and balance. This value since it exceeds $50 \%$ and in the context of research conducted in the field of Social Sciences according to Stevens (2002) is acceptable. Myers (1990) considers that the value of the $R^{2}$ index should exceed $70 \%$.

The adjusted coefficient of determination (Adjusted $\mathrm{R}^{2}$ ) with a value of $98.0 \%$ is essentially a correction of $R^{2}$ which in essence offsets its possible bias, which also receives a high predictive value. According to Stevens (2002) a model shows high predictive power since the value of the ratio $n / k$ is greater than 5 , where $n$ is the sample size and $\mathrm{k}$ is the number of predictors. In the reciprocating model we are considering this ratio is equal to $378 / 4=94.5$.

Regarding the $\mathrm{R}^{2}$ Change index we observe that its initial value in model 1 was $72.0 \%$ when only the variable strictness was introduced in the model. In the second model the introduction of the second variable density added to the value of $\mathrm{R}^{2}$ Change equals to $23.5 \%$, in the third model the independent variable added an additional $12.0 \%$ and finally in the fourth model the balance variable an additional percentage of $18.0 \%$.

The sign indicator $F$ Change contains the statistical significance levels of each variable. Indeed, the introduction of the variables strictness, density, GDP_head, and balance is statistically significant and takes the values $0.000 / 0.000 / 0.034$ and 001 , respectively for each model. Therefore the inputs of the independent variables mentioned above and in the order in which they were introduced are considered important since they all take values that are greater than the input criterion in the model that was set $(0.0005)$.

In Table 8, column B contains all the information about the five parameters of the regression analysis equation including the fixed term. The estimated equation constructed based on the data of our sample with the use of the Stepwise method. It takes the following form:

min_wage $=[(3723.293) . \quad$ (strictness $)]+[(79.274)$. (density) $]+[(0.073)$. (GDP_head) $]+[(-88.046)$. (balance $)]$ $+7535.830$

In the regression equation created we observe that all the coefficients by which the variables are multiplied have positive signs except the coefficient of the balance variable. This means that the 3 predictor variables, strictness, density and GDP head have a positive correlation with the min wage dependent variable, while the balance variable has a negative one. We further find that the greatest effect seems to be exerted by the variable strictness, which in column T presents the largest absolute value $(|25.993|)=25.993$. Thus according to column $T$ the best predictor is strictness with absolute value | 25.993 I , followed by decreasing weight taking into account their absolute values, the density variables with absolute value | 13.532 |, the GDP_head with absolute value | 4.119 | and finally the balance with absolute value $|4.000|$.

\section{Control of admissions}

\section{Independent control admissions}

The independent control admission is satisfied with three ways:

- With the help of the scatterplot of studentized residuals against the sequence of observations (Figure 1). Contains a random distribution of residuals above and below the imaginary horizontal line, starting at point zero. There are neither systematic, non-uniform 


\section{Dependent Variable: Minimum wages in US \$ const:}

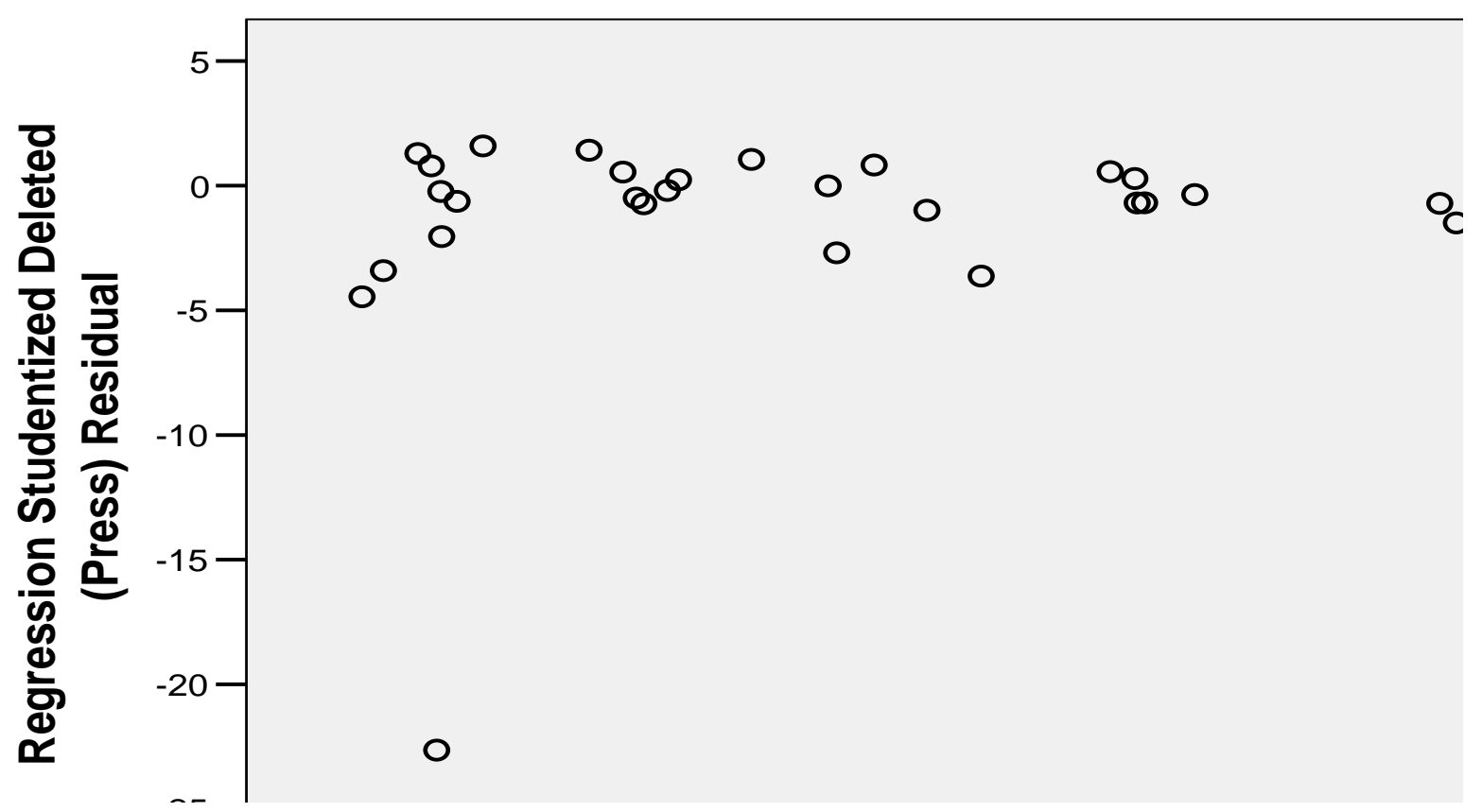

Figure 1. Studentized residuals against the sequence of observations.

accumulations of points (systematic clustering) nor patterns (patterns).

- With the help of the statistical index the Durbin-Watson statistical indicator (Table 7). As the indicator has a score between 1.5 and 2.5 (in our case 1,990) the observation of independence is ensured. Apart from this, the number of observations (378) is a multiple of the number of predictors.

- According to Dafermos (2005) if the number of cases participating in the analysis (in our case 378 ) is much greater than the number of coefficients of our regression model, including the fixed term (in our case 5), then the control of the acceptance of independence is satisfied. In our case this is exactly what happens $(378>5)$.

\section{Control of distribution regularity}

One of the main research concerns during the regression procedure is the possible violent interruption of regularity. Figure 2 shows that standardized residuals follow the regular distribution with a Gauss Bell to have symmetry and normality in how values are distributed.

Moreover in Figure 3, normal p-p plot of regression standardized residual, where the vertical axis has the cumulative frequencies of the dependents' predictor expected values, while the horizontal presents the cumulative frequencies of the dependents' predictor observed values, we note that, because the figure dots are very near the line bisecting the $x$ and $y$ axes, we have a very clear indication of the approximate normality of our regression.

\section{Control of linearity and disseminate equality admission}

Following below is Figure 4, which shows a scatter plot of deleted residuals against predicted values, satisfies the linearity and disseminates equality admissions, with patterns and systematic clustering absence.

\section{Multi-linear evaluation control}

In Table 9 and in Eigen values of covariance matrix column, we observe that none of the variables is zero (0) and that only the index of the balance approaches dangerously (0.004).

Additionally, in Table 8 where tolerance factor is analyzed, we observe that it has values from 0 to 1 . When an independent variable has a tolerance near 1 , it means that only a very small percentage of its distribution can be explained by other independent variables, which happens exactly in our case. Also in the same Table 8 and for the variance inflation Factor VIF, when it does not exceed 10 
Dependent Variable: Minimum wages in US \$ constant prices at 2018

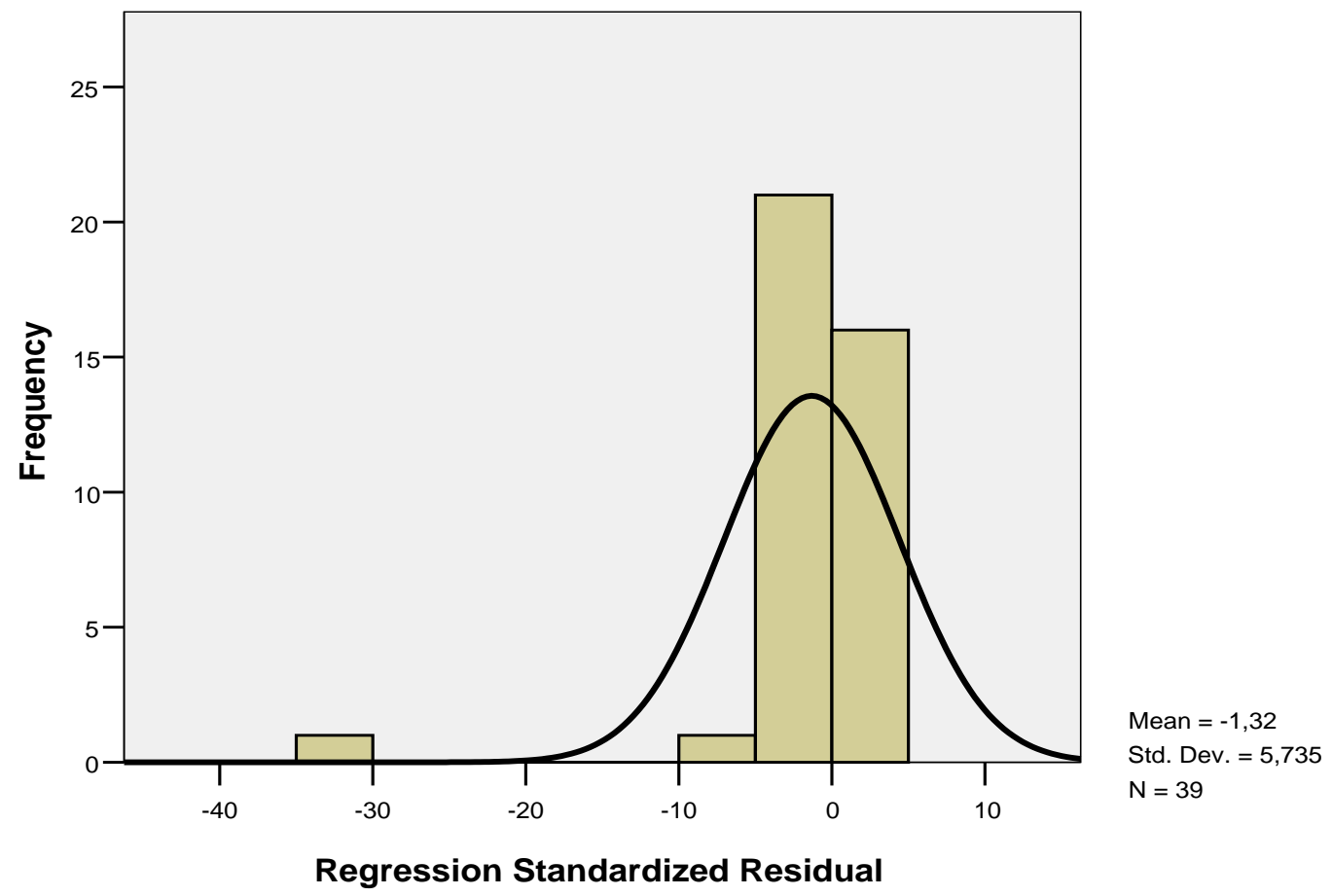

Figure 2. Regular distribution of standardized residuals.

\section{Dependent Variable: Minimum wages in US \$ consti}

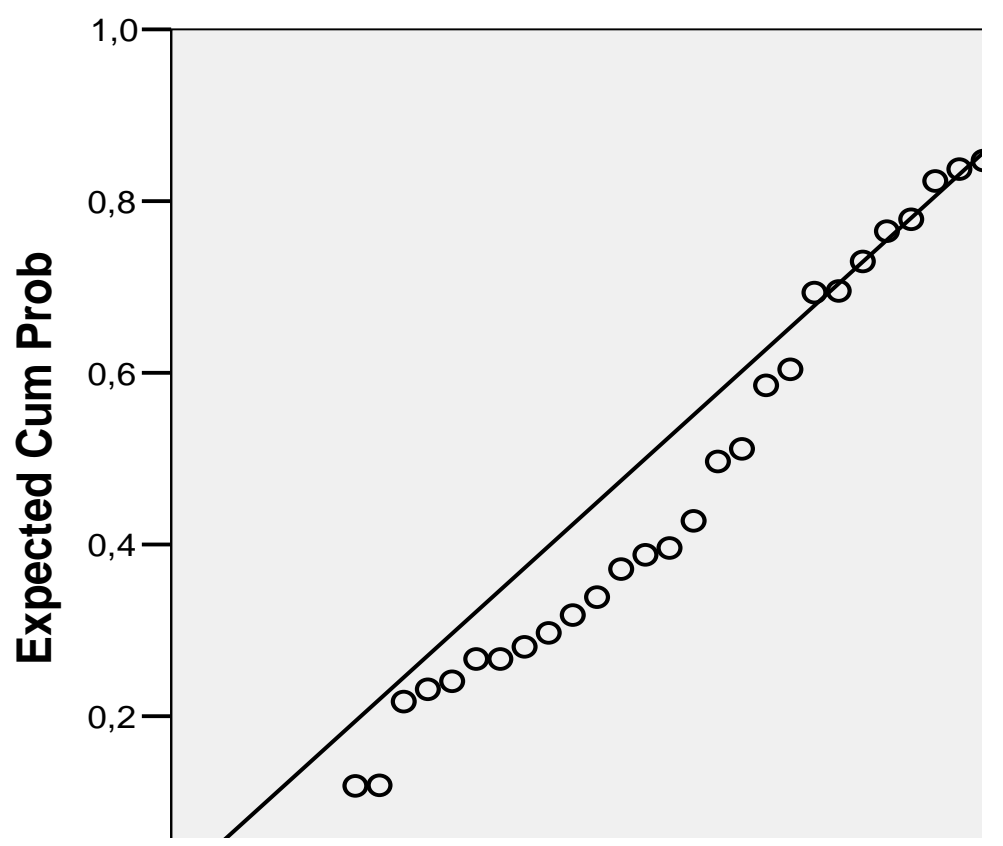

Figure 3. Normal P-P plot of standardized residual regression analysis. 


\section{Dependent Variable: Minimum wages in US \$ const}

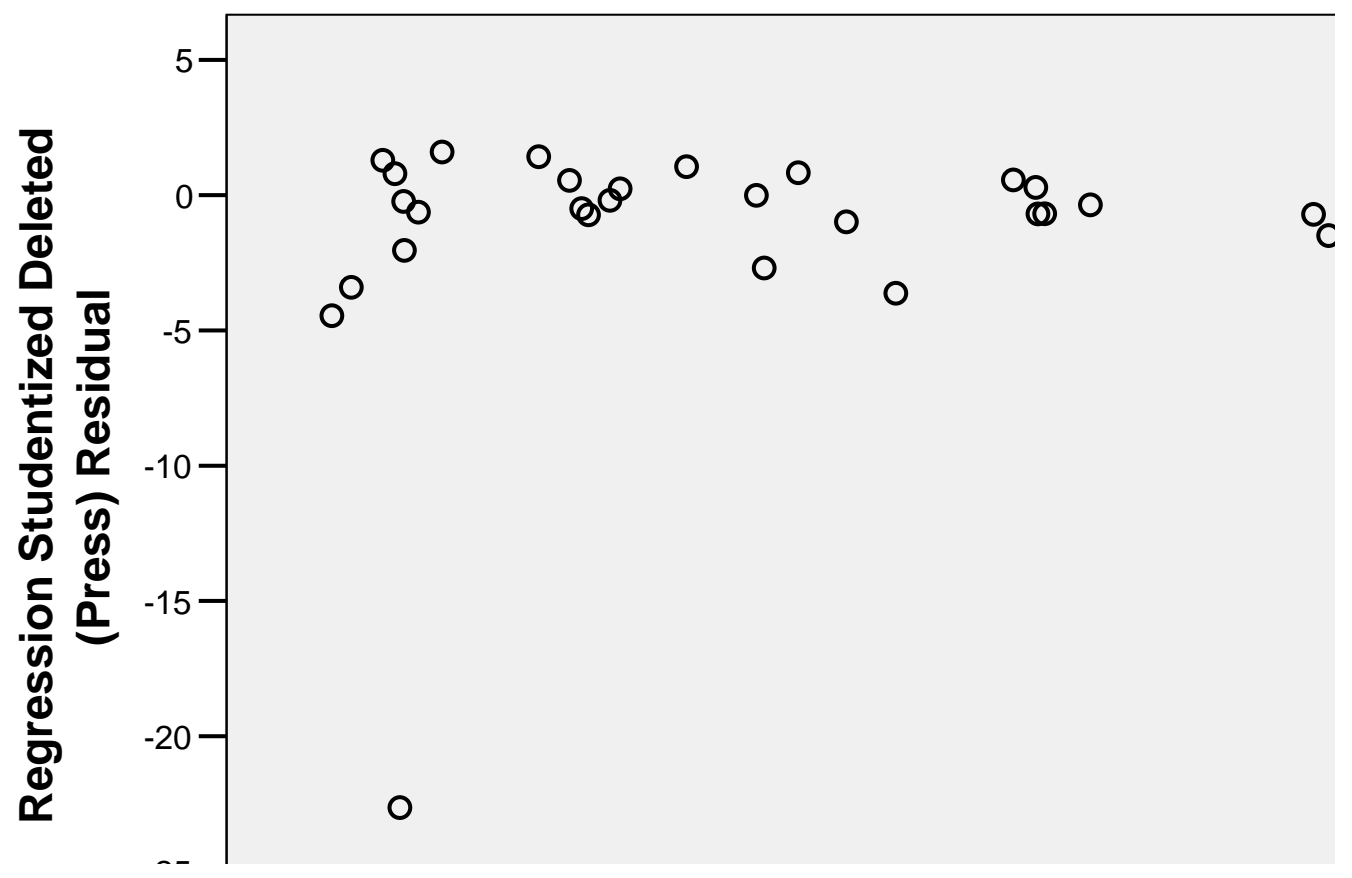

Figure 4. Deleted residuals against predicted values.

Table 9. Collinearity diagnostics.

\begin{tabular}{ccccccccc}
\hline \multirow{2}{*}{ Model } & \multirow{2}{*}{ Dimension } & \multirow{2}{*}{ Eigenvalue } & \multirow{2}{*}{ Index } & \multicolumn{5}{c}{ Variance Proportions } \\
\cline { 5 - 9 } & & & Constant & Strictness & Density & GDP_head & Balance \\
\hline 4 & 1 & 4.329 & 1.000 & 0.00 & 0.00 & 0.01 & 0.00 & 0.01 \\
& 2 & 0.392 & 3.323 & 0.00 & 0.01 & 0.02 & 0.00 & 0.54 \\
& 3 & 0.250 & 4.160 & 0.00 & 0.06 & 0.40 & 0.00 & 0.00 \\
& 4 & 0.024 & 13.334 & 0.05 & 0.29 & 0.57 & 0.12 & 0.25 \\
& 5 & 0.004 & 31.686 & 0.95 & 0.64 & 0.00 & 0.88 & 0.20 \\
\hline
\end{tabular}

there is no problem of Multi-linear evasion (Myers 1990), which also exists in our analysis.

\section{Results for the less developed countries}

Performing the procedure in a similar way in our second sample, looking at Table 10, we find that the DurbinWatson index takes a value of 0.771 which means that there is a strong positive correlation between the adjacent observations, which makes the continue of the analysis in this sample impossible.

(a). Predictors: (Constant), strictness (b). Predictors: (Constant), strictness, density

(c). Predictors: (Constant), strictness, density, GDP_head

(d). Predictors: (Constant), strictness, density, GDP_head, balance

(e). Dependent Variable: min_wage

Is no problem of Multi-linear evasion (Myers 1990), which also exists in our analysis.

\section{Conclusion}

Most of the developed and less developed countries have adopted minimum wage regulation. Although the sectors 
Table 10. Model summary.

\begin{tabular}{ccccccc}
\hline Model & R & R square & Adjusted R square & R square change & Sig. F change & Durbin Watson \\
\hline 1 & $0.848(\mathrm{a})$ & 0.719 & 0.712 & 0.719 & 0.000 & 0.711 \\
2 & $0.877(\mathrm{~b})$ & 0.769 & 0.757 & 0.049 & 0.007 & 0.048 \\
3 & $0.890(\mathrm{c})$ & 0.792 & 0.776 & 0.024 & 0.01 & \\
4 & 0.909 (d) & 0.827 & 0.807 & 0.034 & 0.74 \\
\hline
\end{tabular}

and fraction of workers covered are small given the low rates of formality and urbanization in developed and less developed countries, as the number of covered workers grows, wage regulation will become increasingly significant for the economy as a whole. In addition, there can be spillover effects in uncovered sectors, which can be exacerbated, as we show in the paper, when wage regulation is particularly progressive.

The basic aim of this research was to investigate the relationship between minimum wage in two samples (developed and less developed countries) and different macro-economic measures or other State indicators. Research was carried out on both samples, making it impossible for the sample of less developed countries to be continued. The research aim was achieved through the sample of developed countries with the creation of a regression equation, presented in column $B$ of Table 8 (coefficients), showing all the data of the 5 regression parameters. All variables in the equation affect the configuration of the dependent variable "minimum wage". In the regression equation created we observe that all the coefficients by which the variables are multiplied have positive signs except the coefficient of the balance variable. This means that the 3 predictor variables strictness, density and GDP_head, have a positive correlation with the dependent variable "minimum wage", while the balance variable is negative.

We further find that the greatest effect seems to be exerted by the variable strictness, which in column $t$ also presents the largest absolute value $(|25.993|)=25.993$. The second objective was to verify the degree of influence of all the model's variables, in which the values of used variables were counted via extraction and interpretation of the regression equation. However, based on the statistical importance levels, that correspond to the $t$ values of Table 8 , the best predictor variable is strictness, followed by density, GDP head and balance. Even if the hierarchy is considered (Dafermos, 2005), as more representative of variable value, it would nevertheless not be wise to interpret their numerical classification in an absolute way because of the reserve of t prices theoretical approach.

However, the current research has numerous restrictions. Findings cannot be generalized without verification. Thus, there is a need for more extensive research using another sample with the use of another kind of dependent variable and other independent variables. Also, research on the examination of each variable that influences output separately should be realized and will be one of the authors' next works, in order to compare the occurring results.

\section{Limitations of the research}

The fact that the Durbin Watson test showed a positive correlation in less developed countries between the adjacent observations did not let us to continue the analysis in this sample so the results cannot be generalized in them.

\section{Implication of the research}

The results occurred can constitute a useful tool both for academics and policy makers in planning and making decisions about the minimum wage and the factors affect on it in developed countries.

\section{REFERENCES}

Bayo-Moriones A., Galdon-Sanchez J. E. \& Martínezde-Morentin S. (2013). The determinants of pay settlements: the influence of the national context. Int. J. Hum. Resour. Manage. 24(3):579-600. DOI: 10.1080/09585192.2012.694110

Bhorat H., Kanbur R. \& Stanwix B. (2017). Minimum wages in subSaharan Africa: A primer. The World Bank Research Observer, p.lkw007.

Brosnan P. \& Wilkinson F. (1988). A national statutory minimum wage and economic efficiency. Contribut. Polit. Econ. 7(1):1-48.

Brosnan P. (2003). 'The political economy of the minimum wage. In: B. Burchell, S. Deakin J. M. \& Rubery J. (eds.). Systems of production: markets, organisations and performance. London: Routledge. Pp. 192212.

Brown D., Ingram P. \& Wadsworth J. (2004). The price is right? Pay settlements and nominal wage rigidity in Britain. Brit. J. Industr. Relat. 42(3):507-525.

Brutel O. (2019). The effects of the new statutory minimum wage in Germany: a first assessment of the evidence. J. Labour Market Res. 53(10):1-13.

Bryson A. \& Forth J. (2008). The theory and practice of pay setting. In: The sage handbook of industrial relations, Eds. P. Blyton, N. Bacon, J. Fiorito and Edmund Heery, London: Sage Publications. Pp. 491-520.

Burchell B., Deakin S., Michie J. \& Rubery J. (2003). Systems of production: Markets, organisations and performance. London: Routledge. Pp. 192-212.

Coakes S. J. \& Steed L. G. (1999). SPSS without Anguish. New York: John Wiley and Sons Inc. 
Dafermos V. (2005). Social statistics with SPSS. Thessaloniki: Publications Ziti.

Deakin S. \& Wilkinson F. (2005). The law of the labour market: Industrialization, employment and legal evolution. Oxford: Oxford University Press.

Edwards P. \& Gilman M. (1999). Pay equity and the national minimum wage: what can theories tell us? Hum. Resour. Manage. J. 9(1):20-38.

Field A. (2000). Discovering statistics using SPSS for Windows. Advanced techniques for the beginner. Beverly Hills CA: Sage publications.

Forth J. \& Millward N. (2000). Pay settlements in Britain. Discussion Paper no. 173, National Institute of Economic and Social Research, London.

Hirsch B. T., Kaufman B. E. \& Zelenska T. (2015). Minimum wage channels of adjustment. Indian Relations. 54(2):199-239.

International Labour Office, Laborsta, (2020). International labour office, Laborsta statistics, obtained through the Internet: www.ilo.org/global/What_we_do/Statistics/lang--en/index.htm [accesed 16-9-2020].

Low Pay Commission (2015). National minimum wage. Low Pay Commission Report. London.

Metcalf D. (2008). Why has the British national minimum wage had little or no impact on employment? J. Indian Relat. 50(3):489-512.

Myers R. (1990). Classical and modern regression with applications $\left(2^{\text {nd }}\right.$ Edition). Boston, MA: Duxbury Press.

Nurosis M. (2002). SPSS 11.0 Guide to data analysis. Englewood Cliffs: Prentice Hill.
Organization for Economic Co-operation and Development (2020). Statistical extracts. Retrieved from the complete database available via OECD's Library http://stats.oecd.org/Index.aspx?DatasetCode=PDYGTH

Raurich X., Sala H. \& Sorolla V. (2009). Labour market effects of public capital stock: Evidence for the Spanish private sector. Int. Rev. Appl. Econ. 23(1):1-18.

Rubery J. (1997). Wages and the labour market. Brit. J. Industr. Relat. 35(3):337-66

Saget C. (2008). Fixing minimum wage levels in developing countries: Common failures and remedies. Int. Labour Rev. 147(1):25-42.

Schmitt J. (2015). Explaining the small employment effects of the minimum wage in the United States. Indian Relat. 54(4):547-581.

Stevens J. (2002). Applied multivariate statistics for the social sciencies. Fourth Edition, LEA

Traxler F., Blaschke S. \& Kittel B. (2001). National industrial relations in internationalized markets. A comparative study of institutions, change and performance. Oxford University Press.

Wilkinson F. (1983). Productive systems. Cambridge J. Econ. 7(2):413429. 